\title{
Los gestos de hospitalidad en el oficio de educar
}

The Hospitality Acts in the Teaching Profession

Artículo de investigación | Research paper

Fecha de recepción: 22 de febrero de 2019

Fecha de aceptación: 20 de junio de 2019 Fecha de disponibilidad en línea: febrero de 2021

doi: 10.11144/Javeriana.m14.ghoe

Daniel Gómez-Ramos danielgomezramos84@gmail.com

Universidad NaCional de EdUCACIÓN, UNAE, ECUador (iD) ORCID: https://orcid.org/0000-0002-4041-1512

Para citar este artículo | To cite this article Gómez-Ramos, D. (2021). Los gestos de hospitalidad en el oficio de educar. magis, Revista Internacional de Investigación en Educación, 14, 1-24. doi: 10.11144/ Javeriana.m14.ghoe 


\title{
Resumen
}

Este artículo de investigación parte de la inquietud por colocar en el centro del trabajo educativo el cuidado y la responsabilidad ética ante la vida de los estudiantes: estos saberes favorecen sus procesos de aprendizaje y crecimiento personal. Desde un enfoque inspirado en la investigación de la experiencia y la fenomenología-hermenéutica, se acompaña a una maestra y sus alumnos en situación de vulnerabilidad. La descripción de escenas y las conversaciones con la maestra han permitido pensar los acontecimientos y producir comprensiones pedagógicas. Los resultados muestran cinco hilos de sentido desde los cuales reflexionar y practicar los gestos de la hospitalidad en educación.

\section{Palabras clave}

Cuidado del niño; educación; escuela; ética; práctica pedagógica; relación profesor-alumno; responsabilidad

\author{
Abstract \\ This article stems from the concerns related to the care and \\ ethical responsibility regarding the student's life as the core \\ of the educative work. This knowledge favors their processes \\ of learning and personal growth. Based on an approach \\ driven by the experience research and the hermeneutics- \\ phenomenology, this work is developed as an accompaniment \\ to a teacher and her vulnerable students. The scene \\ descriptions and conversations with teachers have allowed \\ thinking about the events and gain pedagogical insights. \\ The results show five lines of thought useful to reflect and \\ implement the hospitality acts in education.
}

\section{Keywords}

Responsibility; education; teaching practice; student teacher relationship; child care; ethics; schools 
Descripción del artículo | Article description

Este artículo de investigación se deriva del proyecto I+D+i

Relaciones educativas y creación del currículum: entre la experiencia escolar y la formación inicial del profesorado. Indagaciones narrativas de la Universidad de Barcelona (España). Las reflexiones resultantes resaltan la trascendencia de la atención y el cuidado de la vulnerabilidad para una relación pedagógica lograda.

\section{Introducción}

Este trabajo es fruto de un proyecto de investigación ${ }^{1}$ que tiene el propósito de estudiar los saberes profesionales de docentes que, al establecer relaciones de cuidado con sus alumnos, hacen posible que estos prosperen en su aprendizaje y crecimiento personal. El interés global es profundizar en la comprensión sobre la responsabilidad y el cuidado de niños y jóvenes en el oficio de educar (Jordán, 2015; Mínguez, 2012; Noddings, 2003). Los resultados dan cuenta del sentido ético que sustenta y guía esta actitud pedagógica y cómo influye en las relaciones educativas que mantenemos con niños y jóvenes. Otra contribución de este trabajo es la concreción de algunas de las disposiciones y de los gestos mediante los cuales se manifiesta el "cuidado responsable del otro" en la práctica cotidiana.

Las aspiraciones mencionadas han motivado un estudio del cuidadoresponsabilidad como un saber producido en una relación de pensamiento con la experiencia vivida, un modo de saber existencial y holístico que se elabora por medio de un pensar creativo con lo que se vive (Ayala, 2018; Clandinin, 2013). Es un saber emergente, porque dispone a interrogarse por lo adecuado ante una situación singular; pero también es sedimentado, en cuanto proporciona un bagaje reflexionado y una orientación para la acción (García \& Lewis, 2014; Korthagen, Kim \& Greene, 2013).

Con el objetivo de percibir las cualidades del fenómeno estudiado con mayor claridad y amplitud de matices, la indagación se desarrolló en una escuela ubicada en un contexto empobrecido de la periferia de Barcelona, a la que asistían niños en particulares circunstancias de vulneración, acompañando a una maestra de extensa trayectoria profesional y especialmente preocupada por el cuidado de la infancia y la responsabilidad pedagógica.

1 Relaciones educativas y creación del currículum: entre la experiencia escolar y la formación inicial del profesorado. Indagaciones narrativas (EDU2016-77576-P), I+D+i financiado por el Ministerio de Ciencia, Innovación y Universidades para el período 2017-2019, y dirigido por el doctor José Contreras Domingo, de la Universidad de Barcelona. 
Para ello, se realizó una observación participante en el grupo P5 de Educación Infantil a lo largo de un curso escolar, compartiendo el día a día en el aula y manteniendo conversaciones reflexivas con la maestra (María) acerca de las cuestiones suscitadas durante la jornada.

La intención de la investigación no fue ahondar en los saberes propios de la maestra ni identificar y documentar las buenas prácticas de su proceder, sino recibir sus formas de hacer y de pensar como situaciones experienciales (Contreras, 2013). Es decir, acontecimientos novedosos que requerían ser pensados por la investigación para producir los sentidos y los significados que revelarían las diversas dimensiones pedagógicas que la responsabilidad y el cuidado verifican en el mundo empírico (Jay, 2009).

\section{Referentes conceptuales ${ }^{3}$}

El encuentro con la llamada de la vulnerabilidad de un niño es un acontecimiento ético, puesto que su singularidad solicita ayuda mediante una respuesta concreta y situacional: reconocerlo, acogerlo sin condiciones y ofrecerse a acompañarlo (Bárcena \& Mèlich, 2014). La relación pedagógica hunde sus raíces en la responsabilidad ética, en la radical dependencia del otro de nuestra escucha, atención y cuidado, y de que nuestra respuesta debe hacerlo progresivamente responsable de sí y del otro. Según Lévinas (1977), el lazo social se anuda en la preocupación y ocupación por el prójimo, pues lo que da sentido al yo es cuidar del otro; de hecho, la responsabilidad es la estructura esencial, primera y fundamental de la subjetividad.

¿Qué implicaciones pedagógicas tiene esta disposición subjetiva? ¿Mediante qué gestos se materializa en la relación educativa? ¿Cómo opera el lenguaje ético del cuidado responsable? ¿Qué efectos tiene en la subjetividad del niño?

Tomar conciencia de lo extraordinario de la llegada de un niño o joven implica dejarse conmover por la vulnerabilidad de su condición, lo cual demanda al educador volverse sensible, vulnerable y receptivo a la experiencia afectiva y emocional que abre al yo al encuentro con la alteridad. Dice Van Manen (2015) que la responsabilidad pedagógica brota en uno cuando percibe las necesidades de un niño o joven y se siente reclamado a

2 Para preservar la intimidad y cuidar a la docente y a los niños con los que trabaja, se ha decido usar nombres ficticios; del mismo modo, tampoco se hace mención de espacios ni lugares concretos, para que el centro educativo donde trabaja no pueda ser reconocido.

3 Este apartado esboza un primer enfoque conceptual, puesto que las referencias teóricas se van desarrollando a lo largo de todo el cuerpo del artículo, con el objetivo de sostener la actividad indagadora. 
responderlas haciéndose cargo de su vulnerabilidad. Solo entonces, siendo sensibles a la fuerza de su fragilidad y de sus preguntas, escuchando su voz como una interpelación y experimentando la llamada del niño como responsabilidad — como la exigencia de su alojamiento educativo—, los adultos estamos en posición de hacer algo cuidadoso por él.

A partir de una escena escolar y de fragmentos de conversación con la maestra, este artículo centra su foco de interés en el análisis de las claves éticas que nutren el sentido pedagógico de la hospitalidad (Derrida, 2007). La indagación describe algunas disposiciones, gestos y tonalidades que orientan la práctica del acogimiento en el oficio de educar. Se ha entendido la donación de hospitalidad como la actitud receptiva y de apertura subjetiva ante la llegada del otro (Butler, 2009). Hospitalidad ha significado, también, ofrecimiento de un "buen lugar para vivir" e inscripción de la infancia en una cultura común. La presencia del niño representa para el educador una demanda de respuesta atenta y solícita: acogerlo sin ponerle condiciones. La posibilidad del encuentro con el niño pasa por no tematizarlo ni reducirlo a categorías; para que la relación sea "educativa" debe ser, primero, relación "ética" y preservar el misterio de su radical alteridad (Van Manen, 2010).

\section{Metodología}

Dada la complejidad epistémica del saber pedagógico, esto es, que no se deja reducir a técnicas y procedimientos, pues su carácter es integrado, relacional, emocional, corporal, valorativo y ético, se decidió configurar una metodología inspirada en la investigación de la experiencia educativa y en la fenomenología-hermenéutica (Contreras \& Pérez de Lara, 2010; Dewey, 1998; Gadamer, 1977; Van Manen, 2003) con el objetivo de pensar con la experiencia y producir sentido. Esta disposición subjetiva de indagación supone habitar la escuela como sujeto de exposición y recepción de la alteridad de los otros, del mundo y de uno mismo; implica atender y captar el fenómeno como algo que, al acontecer, provoca en la sensibilidad una inquietud educativa; un afecto que da forma a un signo o hilo de sentido, que solicita de la conciencia una significación mediante el pensamiento (Arbiol, 2018).

Si algo resuena subjetivamente es porque la situación vivida despierta una pregunta o conecta con una necesidad, signos que hablan de una búsqueda de sentido pedagógico. El hilo de sentido es experimentado por la reflexividad como el acontecer de una exterioridad que nos "deja pensando" o que nos "da que pensar". Desde diversas orientaciones (Alliaud, 2010; Biesta, 2017; Korthagen et al., 2013) se entiende el acontecimiento 
como un encuentro entre la experiencia y el pensamiento que tiene el poder de extrañarnos de lo conocido, desplazarnos del propio punto de vista, incomodar nuestros presupuestos y hacernos dudar de nuestras palabras. Lo que acontece contiene la posibilidad de producir una nueva elaboración de los significados de nuestras acciones y actitudes.

Los momentos metodológicos pueden enumerarse con la siguiente secuencia: 1) percepción del fenómeno, 2) escritura en el diario de campo, 3) grabación y transcripción de conversaciones, 4) dilucidación de interrogantes e hilos de sentido, 5) construcción de escenas y fragmentos - textos de campo-,6) amplia consulta de corpus teórico y 7) comprensión a través del ensayo como modo de interpretación y reflexión —-textos de investigación-. Durante el proceso se llevó a cabo una triangulación ambiental (Okuda \& Gómez, 2005): al regresar cada día a la escuela, lo observado y analizado volvía a confrontarse y dilucidarse de modo que diera origen también a una nueva revisión y alimentación teórica para, finalmente, desembocar en el tratamiento investigativo como una comprensión más profunda y contextualizada del tema estudiado. De esta manera la escritura resultante del estudio se torna un producto confiable en cuanto permite al lector reconocer en el texto sus inquietudes y hacerse sus propias preguntas.

Después de la percepción in situ del fenómeno, en mi diario de campo tomaba notas descriptivas de lo sucedido, vivido y pensado en la escuela, y de las palabras que compartía con la maestra al respecto. A partir de esas anotaciones, relataba una narración en forma de escena (ESC) o fragmento de conversación (FC); un texto de campo que no lo dijera todo de la experiencia, que no clausurara su potencia significativa, pero cuya lectura tuviera la capacidad de suscitar los interrogantes que se me habían desvelado (Zambrano, 2011).

Una escena o un fragmento de conversación muestran un material sensible con el cual seguir elaborando un pensar con la experiencia, con el cual trazar diversos caminos de escritura mediante los cuales se pueda ir ahondando reflexivamente (Foucault, 1988) en las dimensiones pedagógicas que había implicadas en el fenómeno registrado. El diálogo entre los textos del material experiencial-sensible y la documentación teórica de literatura pedagógica y filosófica fue descubriéndome temáticas de investigación, enfocando con precisión mis preguntas y captando los hilos de sentido susceptibles de ser explorados.

Para los textos investigativos se empleó la escritura ensayística (Adorno, 2003; Lukács, 1970), que permitió sostener un trabajo de ampliación y profundización en el abordaje de las cuestiones educativas que residían en los textos compuestos durante la estancia en la escuela. Porque el ensayo procede indagando experimentalmente con el tema de estudio 
desde diversas vertientes, y lo hace estableciendo con lo vivido una distancia poética: creando, revelando o trayendo al presente algo valioso (Agamben, 2005). Pues el lenguaje del ensayo es un lenguaje con alguien dentro, un lenguaje frágil y heterogéneo, cuyas palabras se quieren evocativas pero siempre preocupadas por la pluralidad y la transferencia de conocimiento de la investigación educativa.

\section{Resultados y discusión}

Como resultados se presentan cinco hilos de sentido tejidos en una trama de categorías cuya elaboración fue realizada a partir de la articulación entre: 1) los propósitos de la investigación, 2) la experiencia vivida en la escuela, 3) la identificación de diferentes signos de los acontecimientos y 4) la elaboración conceptual (Deleuze \& Guattari, 2013) mediante un pensamiento entendido como producción de nuevos efectos de sentido, que tratan de hacer justicia a la multiplicidad semántica de lo real (Larrosa, 2010). Dado que el estudio es más amplio, a continuación se muestran algunos de los asuntos más relevantes sobre los que se ha decidido investigar con mayor exhaustividad.

\section{La práctica cotidiana de la acogida}

"iEstoy volando!" — dice Elvira, de seis años, mientras corre en círculos por el aula. Se acerca al pequeño saco de boxeo y da cuatro puñetazos. El resto de los niños están entretenidos en las tareas escolares.

Elvira dice: "Soy un bebé, cógeme en brazos" —y luego prosigue su vuelo por el fondo de la clase. Dice: "Me estoy metiendo un lío" —repite la frase dándose golpes en la cabeza con la mano.

María ha estado observándola sin decir nada. Ahora ha ido hacia ella para tomarla de la mano con delicadeza y decirle: "Venga, Elvira, ya está bien. Tenemos que hacer faena" —y le tiende la mano y la acompaña hacia su silla-.

Cinco minutos después, la maestra trata de explicar algo en la pizarra. De pronto, Elvira comienza a atizar la mesa con las palmas de sus manos. Da un fuerte empujón a la mesa y se separa de ella arrastrando la silla. Algunos niños comienzan a mirarla, distraídos de la actividad. La maestra interrumpe lo que iba diciendo: "Elvira, cariño, a mí me molesta ese ruido. ¿Puedes parar, por favor?" — sorprendida, Elvira se detiene de inmediato-.

La maestra y las criaturas continúan con la actividad. Al poco rato, Elvira se apoya con las manos en el borde de la mesa y hace equilibrios con las patas traseras de su silla. Su mirada flota errante por el aula, recorriéndola sin focalizarse en ningún sitio. Quedándose distante, ensimismada, alza la 
cabeza hacia el techo. Es una escena que se viene repitiendo desde el inicio del curso. A veces son las piernas de Elvira las que sacuden el suelo con un ritmo aleatorio; otras veces acuesta su torso sobre la superficie de la mesa y apoya la cabeza en sus brazos, o, al contrario, su columna cede tanto sobre el respaldo de la silla que se escurre hasta desaparecer bajo la mesa.

Igual parece estar a punto de dormirse que, de repente, estar poseída por una actividad irrefrenable. En cualquier caso, lo que hace María es situarse detrás de Elvira y acariciarle la espalda, la cabeza y la frente. También masajea con suavidad sus hombros. Entonces la niña comienza a relajar la tensión de todo su cuerpo. Parece desinflarse poco a poco, y su cara pierde cierta expresión de alerta o desconcierto. A menudo, si la niña está trabajando con alguna actividad y empieza a agitarse sin percatarse de ello, la maestra sencillamente le dice: "Bravo, Elvira, muy bien" — desde el cariño, con tono respetuoso- (ESC1).

¿Qué expresa un cuerpo agitado? ¿Qué respuesta me demanda? ¿Qué preguntas propician el encuentro? ¿Cómo acoger solícitamente su diferencia absoluta?

Elvira vuela alejándose de los demás. Corre dibujando círculos por el aula, golpea con vigor un saco, golpea con agitación la mesa, pide ser un bebé, pide ser cogida en brazos; movimientos bruscos y acelerados de un cuerpo afectado. Afectos que expresan signos disponibles a una lectura. Signos de una inquietud que nos reclama atención. Una atención dispuesta al servicio de su proceso vital. Lo cual exige que nuestra lectura se abra a su singularidad. Que reconozcamos su otredad en el contacto con su rostro. La acogida debe guardarse de cerrar aquello único que hace a Elvira ser Elvira.

Por el contrario, la mirada diagnóstica (Contreras, 2002) actúa desde imágenes preconcebidas que definen la infancia en función de una categoría abstracta que explica qué es Elvira, lo que no está bien en ella, lo que debería ser, lo que podemos esperar de la niña y lo que no. Una vez caracterizada Elvira por su desviación o desajuste respecto a unos patrones de normalidad, ya sabemos qué hacer con ella: aplicar un tratamiento para introducir su subjetividad dentro de los márgenes de lo "aceptable". Las categorías patológicas no buscan la proximidad y la comprensión de las circunstancias de la vida de un niño, sino identificar su diferencia como un déficit a reparar, atribuyéndole rasgos distintivos que promuevan su "normalización" (Larrosa, 2017). Un orden homogéneo que eliminaría aquello que hace a Elvira única e irrepetible, y facilitaría su inclusión en la lógica de resultados de las exigencias institucionales.

Frente a la llamada de un niño, necesitamos ordenar el significado de nuestra responsabilidad como educadores. Necesitamos comprender, profundizar y organizar nuestra capacidad de acogimiento del otro. Si nos 
concierne lo que le pasa, si tomamos seriamente la vida del niño, estamos en el problema del acogimiento ético. El acogimiento colabora en la filiación simbólica que inscribe al sujeto en una cultura (Meirieu, 1998). Porque nuestras filiaciones de sangre - al nacer - son insuficientes para hacer lo humano en el individuo; necesitamos los gestos de hospitalidad de los otros.

Es posible que la inquietud de Elvira exprese una dificultad de hallar quietud. Quizás la agitación de su cuerpo es una manera de defenderse de la sombra de unos grandes. Tal vez lo que trae la niña a la escuela es un exceso de frustración causado en sus vínculos de origen. Podríamos preguntarnos si se mueve acelerada para escapar de su contexto de filiación. Quizás la acogida oficia como reconocimiento de su existencia, reconfiguración de su herencia, activación de su potencia. ¿Cómo echar de nuevo los dados en el azar que le ha tocado vivir? ¿Cómo barajar de nuevo las cartas que le fueron repartidas?

Podríamos entender la acción de María como recepción del sufrimiento y ocasión de amparo y de aliento. Se trata de dar la oportunidad para que la niña se viva por fuera del lastre psíquico incorporado. La educadora parece decir a la niña "eres bienvenida, aquí tienes un lugar". Gesto de hospitalidad que inscribe a Elvira en una cultura del cuidado. Una cultura que respeta las necesidades legítimas de los diferentes procesos de desarrollo. Pues con la escuela, por fortuna para muchos niños, hay algo más allá de la familia y su entorno (Masschelein \& Simons, 2014).

La solicitud acogedora de María nos da a pensar acerca de qué significa para los niños su presencia. Una presencia que toma diferentes formas de prestar atención según las necesidades de la situación. Acoger a un niño es servir de sostén simbólico para su infancia; es asegurar al niño que no lo dejaremos caer cuando tropiece; es tender la mano propia y esperar la suya. "Venga, Elvira, ya está bien, tenemos que hacer faena", dice María. Invitación a caminar en dirección al mundo (Arendt, 2016), donde la niña pueda ligar su deseo a lo otro y los otros; des-anudarse de aquello que la inquieta y que obtura su curiosidad; enlazar al sujeto con la participación en una cultura y una sociedad donde producir sentidos del vivir.

Para nacer a la humanidad, ¿basta con nacer a la vida? ¿O pasa por responderse a la necesidad de darle a esta una orientación? Y la orientación de la vida, ¿no la encontramos en relaciones de proximidad afectiva? "Bravo, Elvira, muy bien" es donación de cariño, ternura y respeto, que producen alteraciones en la subjetividad del donatario (Derrida, 1995). El acogimiento desarrolla lo humano en cuanto colabora en la producción de lazos sociales y afecta las formas en que dichos lazos se subjetivan.

La ética de la acogida impide la coacción del niño bajo cualquier marco normativo. Atender su fragilidad entiende que, para sentirse vivo, un niño 
lo hace como puede. Elvira no sabe hacerlo sino moviéndose con agitación; lo hace "molestando"; lo hace reclamando a la educadora "por favor, dime que estás presente, incompleta y disponible". En la escena no vemos a María reprimir las afecciones del cuerpo de Elvira. En ningún caso su mensaje es "no molestes" (castigo), sino "qué necesitas" y "tú puedes" (acogimiento). La relación ética reconoce que la posibilidad del encuentro con el otro requiere que nos hagamos preguntas. Preguntas que reconozcan la alteridad en el rostro del otro (Lévinas, 1977).

La significancia que emerge a través del rostro rebosa la plasticidad de su cara. Rostro no es cara: un mentón, una frente, dos ojos, nariz y boca. Antes que dato perceptible, el rostro es expresión mediante la cual un ser se hace presente para sí mismo (Lévinas, 1977) y para nadie más. El otro es una potencia expresiva que nos interpela desde la distancia. A saber, la relación con el otro no es una relación cognitiva (propia del conocimiento). No puede concebirse dentro de las aptitudes de una conciencia reflexiva. El rostro no puede ser comprendido ni englobado conceptualmente, tampoco visto ni tocado. Definirlo con conceptos implica borrar su alteridad esencial (Lévinas, 1977). La ética atiende la indigencia del rostro para que pueda expresarse sin la intercesión homicida de la representación.

¿De qué intenta zafarse Elvira cuando se mueve tanto? Porque un niño no puede sino molestar, y molestará tanto más cuanto más necesite confirmar que hay un continente para su existencia. ¿Qué respuesta demanda su necesidad de movimiento? ¿Cómo atiendo a un niño que necesita estar agitado para sentirse vivo?

Para que un niño tenga ganas de crecer ha de haber unos adultos disponibles en los cuales confiar y apoyarse; pero también contra los cuales medirse y confrontar tanto los impulsos como las limitaciones. Un niño pide adultos ejemplares que le despierten las ganas de ser, en su otredad, adulto (Van Manen, 2010). ¿No será la agitación de Elvira expresión de esa ausencia de compañía pedagógica? Se podría interpretar que si un niño necesita golpear con recurrencia un saco de boxeo, es porque su cuerpo está cargado de sedimentos de sus mayores. A menudo los mayores depositamos en los niños unas pasiones, unos errores, unas frustraciones y unas melancolías que no hemos sabido resolver. Afecciones que pasan al cuerpo de la infancia como una deuda excesiva de trabajo de elaboración. En esto, ¿qué representa la acogida de un educador para un niño? Tal vez la posibilidad de contar con un otro que le ayude a elaborar aquello que en la familia y lo familiar no tiene lugar.

El síntoma no traduce la afección en tema que borra la singularidad. El síntoma se nos vuelve pregunta ética de hospitalidad (Derrida, 1998). El extranjero arriba con necesidad de alojamiento, y, al entrar en nuestra 
casa, la convierte en hogar y a nosotros en sus huéspedes (Derrida, 2007). El yo enmudece frente a la distancia del extranjero. Tanto su palabra como su silencio zarandean cualquier intento de controlar el encuentro. Sentimos la alteridad de su presencia, nuestra actitud es de escucha pasiva. El recién llegado es una anomalía que trae una exigencia a nuestra receptividad educativa.

¿A qué nos apela su llamada? ¿Cómo atender al desarrollo de lo humano? ¿Cuál es la necesidad que se expresa? Es posible que no haya niños con dificultades de aprendizaje, sino adultos con dificultades de relación ética y pedagógica. "Me estoy metiendo un lío", dice Elvira. Y también "Estoy volando [...], soy un bebé, cógeme en brazos". Si un niño nos inquieta y nos molesta, quizá es porque él mismo está inquieto y molesto. Tal vez no tiene los recursos que le permitirían manejar su orden interno y sosegar su ánimo. Tal vez el niño busque en un educador la compañía de un adulto junto al cual hacer frente a la contundente experiencia de la intensidad que siente cada día en el mundo.

Creo que actúo como un canal para sus sentimientos. Elvira, si tiene cariño, está bien; si no, es fácil que se inquiete. Hoy estaba particularmente movida. Le costaba mantenerse sentada en la silla y atender o hacer las actividades junto a los demás. ¿La has visto? ¿Has notado que hoy está un poco mal? Está nerviosa (María_FC1).

"Un canal para sus sentimientos", dice María. Frente al estado de alarma o de a las armas de Elvira (de defensa y ataque), la maestra responde con el abrazo que cobija y sostiene. Para una niña "armada" (alarmada) es difícil focalizar la atención en la tarea escolar. La maestra es un canal que permite a la niña la expresión de los sentimientos que la afligen; una vía de descongestión de la frustración absorbida por su cuerpo. La cualidad pedagógica de la atención al otro lo libera de una carga que no le pertenece. La idea de ser un canal o una vía nos interroga: ¿qué debe transcurrir entre grandes y pequeños que estructure un espacio de confianza y seguridad? ¿Qué debe circular en la relación para tender lazos entre nosotros y sentirnos bien?

En definitiva, ¿qué nos piden los recién llegados sino un lugar para vivir? Aunque no vale cualquier lugar, no vale un lugar para el mal vivir; no vale un lugar para excluirse del mundo o donde se cohíban sus cuerpos; ni un lugar donde sentir la humillación, la vergüenza y el maltrato de la insignificancia; sino un buen lugar para vivir, que dé ganas de vivir. Un lugar de acogida y amparo, por el que transitar, peregrinar y donde maravillarse por el mundo. Un espacio de relaciones que albergue las heterogéneas formas 
de expresión de la infancia. Configurar un espacio de hospitalidad incondicional: cobijar, sostener, acompañar y dejar partir, serían los verbos de una mirada atenta al otro.

La mirada atenta repara la caída primera de un niño (Esquirol, 2015). La caída que padece cuando siente en su cuerpo la fuerza de la gravedad y tiene miedo de que los otros lo dejen caer. Un trabajo de elaboración que requiere de un buen entendedor, alguien capaz de sostener simbólicamente al niño; alguien que escuche el mensaje que esconde un Ilanto; alguien dispuesto a ponerlo al resguardo de caerse en el abismo. Porque cuando se cancela la posibilidad al sujeto de dar sentido propio y nuevo a su experiencia vivida, el destino de origen se cumple inapelable como reproducción.

\section{La cualidad pedagógica del amor}

Elvira necesita mucho afecto. Si le das cariño está bien, ella funciona. Si ella no tiene afecto se pone mal. Elvira necesita sentir un apoyo, un sostén, un calor. Cuando tiene ese calor ella es Elvira, cuando ella siente que le falta ese calor, es otra persona. [...]

Cuando se tira hacia atrás con la silla o cuando golpea la mesa con las manos, está queriendo decir "iEy, me falta!". Porque es lo que necesita y lo demanda. Atención, cariño, reconocimiento, apoyo... En estos niños hay unas carencias tan grandes, que ellos intentan beber de ti lo que necesitan. Y como maestra del grupo hay una parte que siento que les doy lo que necesitan aunque no esté en el currículum del departamento. Porque lo necesitan tanto a nivel de supervivencia que no hay segundo paso si no satisfacen el primero. No hay aprendizaje si antes no hay esa confianza, esa seguridad. Entonces lo doy en la medida que puedo, esta afectividad, este calor, este "tenerlos presentes", este "me acerco" (María_FC2).

Poner a un niño al resguardo o al abrigo es dar ese "calor" de la cercanía, del que habla María, que protege del frío de la lejanía. Un cariño sin el cual Elvira, cuando sufre su ausencia, "pasa a ser otra persona". La falta de lazos afectivos sinceros deshumaniza, devuelve al sujeto a un estado de barbarie cuasi primitivo (Sloterdijk, 2014). Son el calor, el cariño y la proximidad las gestualidades de una presencia que humaniza. "Amor como fuerza original de la vida, no puede estar limitado, siempre tiene que estar a disposición, y siempre debe ser cumplida en primer lugar" (Wild, 2006, p. 64).

La donación de la acogida es amorosidad o un pensar amoroso en el otro. Amor quiere decir aceptación del otro sin ponerle condiciones y permiso para ser quien necesita ser en cada momento (Wild, 2006); un amor que es la base de la vida y que es imprescindible para respetar los procesos de crecimiento sanos. El niño tiene un potencial particular para desarrollarse 
y una inconcebible necesidad de amor. Según Rebeca Wild (2006, p. 64), "este es el motivo por el que hacen todo lo posible por conseguir algo de amor, aun cuando ello se produzca dando algún que otro rodeo o recorriendo algún camino sinuoso".

Cada vez lo puedo dar un poco más, si ellos van estando más estables emocionalmente. Si no, no lo puedo dar, porque es tan grande la necesidad y la agitación que es casi imposible. Tú lo podrás querer dar o no, pero ellos lo beben. Porque ellos están muy ávidos de calor y de ser contemplados. Es como si alguien tiene mucha sed, si no dispone de una fuente cerca y hay un charco en el suelo, beberá el agua del charco. Y si no hay charco pero hay unas hojas en una planta con la condensación del rocío de la noche, beberá las gotas de agua en las hojas. Aunque la sed, el medio para calmar la sed, sería un vaso de agua. Pero no tienen un vaso de agua. Por tanto, ellos lo beben de ti. [...]

Hay una parte, por ejemplo, cuando he de hacer una contención; la hago con consciencia de que es eso lo que necesita ese niño en ese momento. Entran en una espiral, no tienen freno y se pierden. Ellos no pueden contenerse porque no han podido aprender a regular sus sentimientos. Y hay la parte del currículum, a la que otros niños sí que pueden acceder. En esta parte hay momentos que me desespero, porque todo eso que bebe tanto tiene el carro tan lleno que lo frena muchas veces. Y ahí estamos, con el carro del aprendizaje frenado (María_FC3).

Un niño se pierde en la amenazante intemperie de su fragilidad cuando su demanda de cobijo permanece desatendida. Agitación, sed, frío y desamparo del niño extranjero que solicita lugar de asilo. Un lugar de alojamiento (hospitari), un cálido lugar que dé ganas de vivir. En la escena inicial de Elvira, ¿se podría leer su "iEstoy volando!" como la expresión de perderse en la insoportable y desértica sensación de vacío? Como si la niña deambulara a la deriva en una planicie infinita, donde no encuentra agua ni refugio. Pero precisamente, según Esquirol (2015, p. 128), "es en medio de la planicie desértica donde el rostro del otro aparece como tal pidiendo acogida".

La conversación con María sugiere pensar acerca de una actitud de hospitalidad que predispone al acogimiento. Una actitud que se pregunta sobre la experiencia del niño y sobre qué está pidiendo en su expresión. Los nervios que refleja Elvira en su imposibilidad de hallar quietud, portan un mensaje: "iEy, me falta!". Y lo que le falta es, dice María, "atención, cariño, reconocimiento, apoyo". Esta sería la sed no saciada que la niña trae a la escuela con avidez desesperada. No se trata de una niña con necesidades especiales, sino con la más común de las necesidades: el amor, que es continente para la existencia humana. 
Cuando María habla de "hacer contención" puede traducirse como servir a los niños como sostén para la experiencia cotidiana de su vulnerabilidad. En definitiva: contener, sostener y albergar el padecimiento de la indefensión y de la fragilidad de ser un recién llegado a un mundo que no se conoce (Bárcena, 2012). Un mundo que llevará algún tiempo mostrar al niño, narrárselo, describírselo, para que no le tenga miedo y lo pueda disfrutar. Todo niño recién llegado a este mundo, para poder desarrollar las cualidades humanas, necesita la seguridad de que es amado en todas las situaciones (Wild, 2006).

En la ausencia de alguien con disposición atenta para darle un vaso de agua, el niño se arrodillará a calmar su sed en un charco de lluvia, o lamerá el rocío de las hojas de una planta antes de que el sol despunte. Si aún así no ha saciado la demanda fundamental de agua, el niño reclamará lo que le pertenece por derecho de nacimiento. Y lo hará gritando, llorando, molestando. Lo hará revoloteando por el cielo de la ausencia. Corriendo por los laberintos de la impaciencia. Sacudiendo las mesas, las sillas y nuestros cuerpos. Se lesionará a sí mismo y exclamará "Me estoy metiendo un lío".

Lo que constituye la vida humana es el amor (Maturana, 1998). El amor constituye la aceptación del otro como legítimo otro en la convivencia. Sin relaciones de aceptación mutua, se produce alejamiento y destrucción. Dependemos del amor que es aceptación en el vivir juntos para un desarrollo salutífero. La mayor parte del sufrimiento en la vida humana viene de la negación de este amor. ¿Cómo puede el niño mirarse a sí mismo si lo que ve no es aceptable, si no es lo que debería ser o es lo que no debería ser, pues así se lo han hecho saber los adultos desde los padres a los profesores? (Maturana, 1998).

La necesidad de Elvira es ser contemplada con afecto, dice María. "Sentirse visto significa que se confirma su existencia, que es una persona única y un alumno único", dice Van Manen (2015, p. 39). ¿Cuál es el valor pedagógico de un reconocimiento del otro que lo acepta en su alteridad? ¿Qué efectos tiene la forma en que miro a un niño? ¿Cómo experimenta él mi mirada?

Ver al niño con nuestro cuerpo significa notar la tonalidad de su animus. Escuchar el ritmo de su soplo y su respiración como formando parte de nosotros. Que el otro nos llegue es decir que el otro está viviendo en uno. Sensibilidad que capta las novedades imprevisibles que trae cada día. La especulación sobre alguien reduce su realidad a fantasías y dejamos de verlo en sentido empático. Es la participación y la intervención del otro en "nuestra" realidad lo que permite que su rostro aparezca como único y distinto. Ver al otro supone dejar que algo nos pase en la experiencia de la intensidad de su presencia. El niño se sentirá visto en cuanto yo sienta la 
expresión de su estar existiendo. El prejuicio que etiqueta es ya una condición que prescribe el destino del otro. La tematización del otro es una violencia intersubjetiva. Lo que nos aproxima al encuentro es la consulta hecha con la franqueza del cariño y el respeto: ¿cómo estás?, ¿qué necesitas?, ¿qué quieres decidir?, ¿en qué te puedo ayudar? No en vano, el verbo latino consulere traduce 'deliberar un juicio conjuntamente'.

¿Se podría decir que un educador atento "siente con" el otro? ¿Y que "sentirse con" el otro le permite ser un canal para el "sentirse a sí" del otro? "El adulto 'comprende' en un sentido afectivo la situación de un niño o de un joven" (Van Manen, 2010, p. 110). La maestra habla de "dar afectividad", de "tenerlos presentes" y de "acercarse" a ellos como gestos primordiales de la enseñanza. Dice María que el aprendizaje de los niños pasa por el sentimiento de confianza y seguridad en el aula. ¿Son el acogimiento y la atención a los niños la base para la creación de relaciones con la cultura?

La visión del otro en su vulnerabilidad (ser susceptible a la herida) nos saca de la percepción centrada en nuestro yo. Entonces nuestra mirada lo ve con el cuerpo y estamos en disposición de hacer algo por él (Van Manen, 2010). Cuando vemos su necesidad o escuchamos su curiosidad, nos sentimos personalmente movilizados a acompañarlo. Sus preguntas nos importan y su respuesta nos atañe. Somos inducidos a responder de su vida bajo el sentido de la responsabilidad. En el encuentro con el niño, es él quien nos concede la autoridad pedagógica sobre la base de confianza, afecto y entendimiento que logramos propiciarle (Van Manen, 2010). En última instancia, del niño depende la decisión de elegirnos y conferirnos autoridad en la relación para hacernos responsables de su vida.

\section{El sentido pedagógico de la responsabilidad}

El rostro de un niño ejemplifica la fragilidad humana por ser la piel más expuesta e indefensa. Su desprotección nos recuerda la obligación ética que tenemos con él. No podemos sustraernos de la relación con la debilidad esencial que hay en su rostro. Él solo, el rostro del niño es pura significación. No es identificable el niño, tampoco se deja describir temáticamente. Su presencia tiene sentido en sí misma. La voz que dice o la mirada de sus ojos son ya demanda de respuesta atenta. Lo expresivo en el cuerpo del otro, según Emmanuel Lévinas (2000, p. 82), "me pide como se pide algo que se ordena, como cuando se dice: 'ise os ruega que...!'".

La responsabilidad no brota de nuestro yo, sino del niño cuya presencia nos obliga. La responsabilidad para con el otro no está sujeta a nuestra decisión, sino que es la llamada de su debilidad lo que nos concierne e interpela (Lévinas, 2000). La visión del rostro de un niño (su corporeidad) fractura la coraza narcisista del yo al enfrentarme con su alteridad. El encuentro 
nos impone una separación de nosotros mismos porque su presencia nos afecta. Su proximidad no nos deja indiferentes (Van Manen, 2015); al contrario, nos preocupamos y ocupamos de atender su reclamo.

Los gestos de la hospitalidad son apertura hacia el rostro del niño para acogerlo. Aquello que acogemos es solamente su rostro, su presencia cara a cara, no su reducción al constructo de una imagen. Dar hospitalidad es dar un "sí" al otro; acoger su rostro se traduce como atender su palabra. La oposición entre hospitalidad y tematización es bien clara tanto en Lévinas (1987) como en Derrida (1998): la primera es el principio intencional de la ética y la ética misma. Sin el recibimiento de la acogida, no hay rostro sino borradura tematizada (violencia). El gesto inicial en dirección al niño debe ser la pasividad; pasividad, receptividad y sensibilidad.

Encontrar al otro en el lenguaje es recibir su expresión, en la que desborda en todo momento cualquier pensamiento. Entonces, es recibir del otro más allá de la capacidad de nuestra conciencia reflexiva, lo que significa ser enseñado. Es un encuentro ético, o sea, no alérgico, en el que la palabra del otro es una enseñanza. Pero no el aprendizaje de algo que ya estaba oculto y latente en nosotros mismos, y que el otro nos viene a descubrir, sino que la enseñanza viene del exterior de nuestra mismidad y nos trae más de lo que contenemos: epifanía (Lévinas, 2006).

Más allá de la comprensión y el conocimiento del niño, el yo se abre a la vulnerabilidad de su piel, expuesta a la herida. El yo puede recibirla en cuanto se vulnera a ella. La vulneración aloja una relación de sensibilidad con el niño. Desde ella: yo soy para él. El lazo educativo se anuda solamente como responsabilidad. Que sepamos o no cómo asumirla, que podamos o no hacer algo concreto por el niño es secundario. En el seno de una acogida que está hecha de vulnerabilidad, la palabra yo significa "heme aquí", dispuesto a responder (Lévinas, 1977); movimiento de apertura hacia lo otro absoluto del niño al que estamos éticamente sujetos.

Para Lévinas, son las relaciones de acogida de la alteridad lo que nos confiere subjetividad. Padecer su negatividad supone un acontecimiento formativo del yo, porque imprime una experiencia en sentido enfático. Es decir, el rostro de un niño encausa la atención al sustraernos de vivir para nosotros mismos y convocarnos a vivir para él. Lévinas (1987) define la subjetividad del sujeto en cuanto que hospitalidad y responsabilidad para con el otro. Nuestra condición humana se realiza, entonces, en el compromiso vital con el otro y lo otro. Sin que el yo pierda su "primera persona" del singular: pues él sostiene el mundo (Lévinas, 2000). La constitución de nuestra subjetividad se origina en el encuentro con una exterioridad radical. Por ejemplo: un niño nos asigna como sujetos de su responsabilidad, lo cual desarma nuestras concepciones previas y pone en juego nuestras 
capacidades para ponernos al servicio de su demanda. Por eso, Jacques Derrida (1998) dirá que la ética de la hospitalidad es traumática.

La pasividad de recepción de lo distinto del niño provoca que nuestra subjetividad salga de la empobrecedora trayectoria narcisista. Interrumpe el cierre en sí misma y abre a la relación con su otredad. Esto suspende la atención egológica hacia nosotros mismos y la conduce hacia el niño. Esto que somos es el resultado de que alguien haya respondido de nosotros haciéndose cargo de nuestro cuidado. Alguien que no ha sido inmune ni impune ante la natural fragilidad de nuestro cuerpo (Larrosa \& Skliar, 2009). Alguien que ha escuchado el ruego y la petición que se decían a través de nuestro rostro. Esto que somos es gracias a la atención donada por alguien en una proximidad afectiva. Una proximidad afectiva productora de un entrañamiento entre dos. Trans-formación del uno por el otro - y viceversa- en los movimientos que constituyen una experiencia de relación que respeta las singularidades.

\section{La donación de sí en el vínculo educativo}

Es a pesar del yo ("a nuestro pesar") que los otros nos conciernen. Lo que estructura la subjetividad es el dar. Y lo que da sentido a la vida es, justamente, la donación. Para que el don sea hospitalario se requiere que el donador haga don de sí mismo. Lo que damos es algo de lo propio, algo que nos pertenece, algo que de manera indiscutible es nuestro. La donación más auténtica y valiosa que podemos hacer es, en tal caso, nuestro tiempo (Derrida, 1995).

Donación de sí que imprime una de-subjetivación en el sujeto, o sea, una pérdida absoluta y una herida (trauma). La donación depende de la capacidad de vulnerarse ante el donatario. Gasto sin reservas, el don digno de su nombre es un acontecimiento que altera los cuerpos implicados. De acuerdo con Derrida (1995), es necesario que el don de hospitalidad exceda el círculo económico y la lógica del intercambio (de objetos, capital o símbolos). Más allá del agradecimiento que funciona como retorno a sí y restitución, el don debe ser desinteresado. Se anula si el donador o el donatario lo identifican como tal. Si le otorgamos un sentido, hemos caído, pues, en la trampa de la buena conciencia y la autorreferencia.

Sin esperar retribución, el don es gratuitus; transcurre por fuera del ritual de la deuda. Si existe una voluntad altruista que lo motiva, el don deja de ser don en sentido empático. El don de la hospitalidad exige al donante que este no consiga reapropiárselo, que el don no pueda regresar a él bajo la forma de la reciprocidad. La acogida es incondicional porque no rinde cuentas entre los sujetos. 
Lejos del ámbito de la devolución mutua, la llegada del arribante es repentina, inesperada y sorpresiva. El niño aparece de pronto en el umbral y solo cabe responder afirmativamente a su recepción. No deja que se le impongan condiciones ni que se le controle con un documento acreditativo (¿qué haces aquí? ¿por qué has venido?). No permite reconocimiento ni identificación porque el niño que arriba no ha sido invitado. Tampoco controlado con antelación mediante una descripción temática. No es un invitado susceptible de vigilancia, sino un visitante de nombre desconocido. Un absoluto otro, frente al que hay que aceptar el riesgo de exponernos a su encuentro. Del francés, I'arrivant traduce 'aquel o aquello que viene' y también 'lo que sucede o lo que pasa': de ahí que la incondicionalidad de la hospitalidad represente un acontecimiento ético (Derrida, 2007).

Que el niño es un absoluto otro significa que no debe haber tematización ni descripción que defina al recién llegado. Si lo reducimos a una categoría identificable, instauramos una relación de posesión (instrumentalización), que borra la traza de su rostro. Desde una inmunidad invulnerable no hay situación ni otro que puedan afectarnos y, por tanto, tampoco encuentro ético ni mucho menos relación educativa. Solo desde nuestra propia vulnerabilidad somos capaces de pensar a un niño y el peso de su forma de vida.

La apertura al otro como exposición subjetiva pasa por vulnerarnos; para decirlo con Derrida (1998), uno debe autoinmunizarse, "protegerse contra su propia protección, su propia policía, su propio poder de rechazo, su propio 'tout court', es decir, contra su propia inmunidad" (p. 67). La investidura, el rol o el papel instituidos ejercen un poder que identifica a los sujetos para reducirlos a categorías que facilitan el control y administración de sus vidas. Eliminando cualquier posibilidad de experiencia y relación ética. En cambio, en la acogida sin condiciones, es la presencia del otro lo que nos regala la posibilidad de acogerlo. Aunque somos nosotros quienes creemos estar recibiéndolo, es él quien nos recibe a nosotros en nuestra casa. En sentido estricto, es él quien hace de nosotros unos anfitriones. Pues sin su llegada no habría hospitalidad ninguna. En último término, el arribante nos acoge en nuestra propiedad, volviéndonos huéspedes suyos. Por este motivo, Lévinas dirá que la casa del yo es el otro, o está en lo otro. "Precisamente, en la medida en que entre el otro y yo la relación no es recíproca, yo soy sujeción al otro; y soy 'sujeto' esencialmente en este sentido" (Lévinas 2000, p. 82). Desde esta perspectiva, Derrida (1998) considera que el sujeto existe en cuanto es interpelado por otro. La subjetividad se conforma en el compromiso de respuesta a lo otro. Incluso a lo otro que hay en uno, se responde. Se responde a una necesidad, a una pregunta, a una desorientación, 
a un límite, a un deseo. Se responde a una singularidad por parte de una singularidad que asiente al compromiso con un "sí" incondicional.

La educación es un fenómeno intersubjetivo que exige a la pedagogía pensar la situación éticamente (Bárcena \& Mèlich, 2014): como respuesta a la llamada de un rostro. La ética pedagógica comprende a los seres humanos como seres que nos configuramos en heteronomía. Y por ello necesitamos vivir en relación, a saber, fuera de nosotros mismos.

\section{Pasividad para recibir el misterio de la infancia}

Dice Derrida (1989) que el encuentro con el otro prohíbe el monólogo. En el otro se presenta lo infinito, sobre el que ningún pensamiento puede cerrarse. El rostro de un niño expresa una infinitud, puesto que ninguna totalidad puede abrazarlo. Un niño es infinito: irreductible a cualquier representación, excede el ideatum en el que es pensado. No puede ser objeto o la simple "realidad objetiva"; el niño es más de lo que podemos pensar. Lo cual quiere decir que desconocemos qué porta, qué carga y qué nos trae un niño al encuentro. Es decir: no sabemos quién es ni lo que puede su cuerpo.

La aparición de su voz y su mirada debe ser para el educador un acontecimiento que le obligue a replantearse qué significa ser educador. ¿Qué significa ser educador de este niño con nombre propio? ¿Qué implicaciones conlleva ser responsable de él? No de cualquiera y en cualquier momento, como si la relación pudiera ser totalizada y comprendida bajo unos parámetros universales. Sino de "este niño de aquí", con nombre y apellidos, distinto de "aquel niño de allí". El sentido educativo no es susceptible de ser convertido en procedimiento y reproducción. El sentido solo hace sentido en la experiencia subjetiva de encuentro con lo único. Emerge como interrogación por lo adecuado en cada momento pedagógico (Van Manen, 2010).

El yo narcisista no puede salir de sí mismo para entrar en relación con lo infinito del otro. Funciona clasificando, controlando y homogeneizando los procesos de subjetivación, que son únicos e imprevisibles. Congelamos e instrumentalizamos al niño, en vez de escuchar su incierta singularidad. Dar al otro una respuesta de atención pide nuestra disposición a padecer una fractura en nuestro ego por la que acceder a una proximidad.

La capacidad de acoger al otro sin imponerle condiciones (te acogeré si tú...) requiere la deposición de la centralidad en el yo. El yo tiene miedo a la exterioridad y a la diferencia, que lo ponen en tela de juicio. La identificación fuerza la existencia del niño a plegarse con la imagen (que tengo en la cabeza) de lo que él debería ser. Pero lo otro es esencialmente lo imprevisible, diría Lévinas (2000). La acogida no se constituye a través del conocimiento sobre el niño; conocerlo es confundirse en lo idéntico a uno mismo, 
y lleva a la supresión de la alteridad. La acogida se basa en una erótica de la confianza, que surge a partir del desconocimiento acerca del otro.

¿Será la pasividad la actitud primordial que acoge al niño? Pasividad como un saber no saber asistemático que recibe lo inconmensurable del niño. Pasividad que no mide ni calcula la vida ajena, busca aproximarse con sensibilidad. Una escucha que suspende el monólogo del yo, que, en la prepotencia de su retórica pedagógica, prescribe el destino de los niños. Donación de respuesta que genera una tensión con el otro, tensión entre respetar la experiencia que le es propia y el compromiso con la orientación de su existencia hacia una relación de cuidado - con el mundo, los otros y consigo-. ¿Qué hacer o no, qué decir o no, cuándo y cómo? ¿Cómo vive el otro la situación? ¿Qué demanda el desarrollo de su condición humana?

Preguntas que no quieren la superación de un obstáculo, sino la configuración de un problema interesante. El problema que nos interesa es cómo encontrarnos con el niño o joven. Y no tiene solución. El encuentro es lo imposible (Derrida, 1995), no porque no pueda efectuarse, sino porque escapa del dominio y la comprobación. Hay obstáculo cuando ya nos hicimos, de antemano, una imagen suya y de lo que queremos conseguir. Las representaciones dificultan el acontecimiento que implica y nos complica el contacto con su existencia.

Desconocer cómo experimenta el otro la situación y qué necesitaría de nuestra respuesta nos pone atentos a su expresividad. El encuentro se da con lo exterior a nuestras concepciones. La voz y la mirada que hay en su rostro expresan un misterio cuya dignidad depende de su salvaguarda. Por tanto, la relación será ética solo si cuestiona el esquema interpretativo desde el que leemos la situación. Ejercicio siempre inacabado, el encuentro problematiza nuestra capacidad de pensarnos junto al otro. Su posibilidad —imposible - exige la donación de algo propio, que es pérdida o duelo de una parte del yo (Butler, 2006).

\section{Conclusión}

Nunca estamos preparados para acoger al otro. Más bien se trata de estar disponibles: abiertos a su llegada. En cambio, el monólogo de nuestro discurso es cerramiento. ¿Qué de nuestra posición debemos mover para albergar una presencia? Una presencia produce alteraciones en la comodidad de nuestros habituales modos de reflexión. No nos deja impasibles: la sentimos, la notamos. Su llegada es irrupción y variación subjetiva, o no es llegada. Acoger a un niño es perturbación, perturabre, que destruye nuestro orden. También destruye nuestra voluntad de ordenarlo bajo un orden. Su aparición acontece como vulnus, herida que nos vulnera en nuestra 
vulnerabilidad. Lo que del otro nos hiere no es sino su herida, su vulnerabilidad. El encuentro tiene lugar entre dos heridas, la una es 'vocación de' y 'camino hacia' la otra.

Las heridas desean curarse entre ellas en una imposible completitud (Derrida, 1989). Deseo incapaz de satisfacción, por eso el deseo nos dirige hacia fuera. En la naturaleza del ser humano hay una carencia insustituible; un hueco, un vacío, una falta que se trueca en dependencia de lo otro. Una vida se humaniza en heteronomía: en relación con los deseos, las heridas y las normas de otras vidas (Butler, 2014). Que el ser humano es frágil significa que podemos rompernos en cualquier momento; que la vida se maneja en la provisionalidad y la incertidumbre; que nuestra esencia es una ausencia, y que la ausencia se expresa como demanda de compañía y de acompañamiento. Demanda que emerge en forma de un llanto, de un grito y de una señal. Señal es signum, que traduce 'signo' o aquello que los hombres siguen (una seña o un estandarte).

El pensamiento se despliega leyendo los signos que significa un niño. El educador sigue las señales que deja su cuerpo, por eso va siempre un paso por detrás. ¿Qué da sentido a su experiencia? ¿Cómo hacer para encontrarnos? La acogida no se hace de una vez, no es extraordinaria sino cotidiana. Su función es inagotable y el educador se dispone a ella cada día. El encuentro es siempre otro encuentro y el recién llegado es siempre otro recién llegado; aunque sea el mismo, su cuerpo es distinto. Aún con el mismo nombre, su rostro es infinito. Estar atento al otro es el carácter de fondo en el buen educador.

La incompletitud motiva la relación social, porque la falta en el sujeto lo conduce a desear a lo otro y los otros, y a ligarse a ellos mediante el lenguaje (Esquirol, 2015). No obstante, la relación educativa no resuelve la condición de incompletitud, sino que la torna habitable gracias a la progresiva introducción de la infancia en la cultura humana y en la gramática del cuidado. "Los recién llegados no están hechos por completo sino en un estado de formación", dice Hannah Arendt (2016, p. 197), y más adelante: "Ante el niño, el maestro [...] le muestra los detalles y le dice 'este es nuestro mundo'" (p. 201). La autora habla de la educación como la decisión de asumir una doble responsabilidad, que ella llama "autoridad" educativa: a) cuidar del pequeño para que el mundo no proyecte sobre él nada destructivo y b) proteger al mundo de la potencia renovadora que trae consigo cada nueva generación.

Según Arendt, el nacimiento de un niño - la experiencia de su llegada al encuentro - representa el acontecimiento de la radical novedad, es decir, la irrupción de una alteridad absoluta que interrumpe el curso normal de las cosas (Skliar, 2018) y nos descoloca de nuestras posiciones, presupuestos y 
expectativas educativas, para coaccionarnos a pensar las condiciones para un nuevo encuentro pedagógico. Es precisamente el acontecer de la natalidad, la presencia del enigma del otro cara a cara (Lévinas, 19774), lo que inaugura la asimetría en la relación, a saber: la responsabilidad del adulto es responder por la vida del niño, sin esperar la recíproca. Pues mediante la educación decidimos si amamos a nuestros hijos lo bastante como para sostenerlos y acompañarlos en el emprendimiento de algo que nosotros no imaginamos, "lo bastante como para prepararlos con tiempo para la tarea de renovar un mundo común" (Arendt, 2016, p. 208).

De ahí que los gestos de hospitalidad sirvan de fundamento para el vínculo educativo, o sea, sin la acogida de la alteridad no hay educación sino más bien adoctrinamiento, dominación y alienación (Biesta, 2017), pero garantizar el alojamiento ético del otro no es suficiente para producir un proceso de aprendizaje.

Sin embargo, las relaciones de cuidado favorecen extraordinariamente las relaciones de enseñanza. Dicho de otra manera, uno aprende más y mejor cuando se siente ayudado, escuchado y contemplado en sus diferencias y en sus singulares modos y tiempos de aprendizaje. Aunque el oficio de enseñar va más allá de la empresa ética, gracias al suelo que la ética configura nuestra práctica puede ser solícita y reflexiva para amplificar sus cualidades pedagógicas (Van Manen, 2010).

\section{Sobre el autor}

Daniel Gómez-Ramos es doctor en Educación y Sociedad de la Universidad de Barcelona, España. Profesor universitario y miembro del grupo de investigación consolidado Esfera, de la Universidad de Barcelona, España. Cofundador del proyecto Universidad Móvil. Imparte cursos, conferencias y asesorías en el área de formación inicial y continua de docentes y educadores(as).

\section{Referencias}

Adorno, T. (2003). Notas sobre literatura. Madrid: Akal.

Agamben, G. (2005). El hombre sin contenido. Barcelona: Áltera.

Alliaud, A. (2010). Experiencia, saber y formación. Revista de Educación, 1(1), $141-157$.

Arbiol, C. (2018). Elementos para una pedagogía de la alteridad en la práctica de educadoras sociales. Teoría de la Educación, 30(2), 109-129.

Arendt, H. (2016). Entre el pasado y el futuro. Barcelona: Península.

Ayala, R. (2018). La relación pedagógica: en las fuentes de la experiencia educativa con Van Manen. Revista Complutense de Educación, 29(1), 27-41.

Bárcena, F. (2012). El aprendiz eterno. Buenos Aires: Miño y Dávila. 
Bárcena, F. \& Mèlich, J. C. (2014). La educación como acontecimiento ético. Buenos Aires: Miño y Dávila.

Biesta, G. (2017). El bello riesgo de educar. Madrid: SM.

Butler, J. (2006). Vida precaria. Buenos Aires: Paidós.

Butler, J. (2009). Dar cuenta de sí mismo. Buenos Aires: Amorrortu.

Butler, J. (2014). Vida precaria, vulnerabilidad y ética de cohabitación. En B. Sáez (Ed.), Cuerpo, memoria y representación (pp. 47-80). Barcelona: Icaria.

Contreras, J. (2002). Educar la mirada... y el oído. Cuadernos de Pedagogía, 311, $61-65$.

Contreras, J. (2013). El saber de la experiencia en la formación inicial del profesorado. Revista Interuniversitaria de Formación del Profesorado, 27(3), 125-136.

Contreras, J. \& Pérez de Lara, N. (2010). La experiencia y la investigación educativa. En J. Contreras \& N. Pérez de Lara (Eds.), Investigar la experiencia educativa (pp. 21-86). Madrid: Morata.

Clandinin, D. J. (2013). Engaging in Narrative Inquiry Walnut Creek. California: Left Coast.

Derrida, J. (1989). La escritura y la diferencia. Barcelona: Anthropos.

Derrida, J. (1995). Dar (el) tiempo. Barcelona: Paidós.

Derrida, J. (1998). Palabra de acogida. Madrid: Trotta.

Derrida, J. (2007). La hospitalidad. Buenos Aires: De la Flor.

Deleuze, G. \& Guattari, F. (2013). ¿Qué es la filosofía? Barcelona: Anagrama.

Dewey, J. (1998). Democracia y educación. Madrid: Morata.

Esquirol, J. M. (2015). La resistencia íntima. Barcelona: Acantilado.

Foucault, M. (1988). El pensamiento del afuera. Valencia: Pre-Textos.

Gadamer, H.-G. (1977). Verdad y método I. Salamanca: Sígueme.

García, J. A. \& Lewis, T. E. (2014). Getting a grip on the classroom: From psychological to phenomenological curriculum development in teacher education programs. Curriculum Inquiry, 44(2), 141-168.

Jay, M. (2009). Cantos de experiencia. Buenos Aires: Paidós.

Jordán, J. A. (2015). La responsabilidad ética-pedagógica de los profesores-educadores: una mirada desde Max van Manen. Revista Española de Pedagogía, LXXIII(261), 381-396.

Korthagen, F. A. J., Kim, Y. M. \& Greene, W. L. (2013). Teaching and learning from within. Nueva York: Routledge.

Larrosa, J. (2010). Herido de realidad y en busca de realidad. En J. Contreras \& N. Pérez de Lara (Eds.), Investigar la experiencia educativa (pp. 87-116). Madrid: Morata.

Larrosa, J. (2017). Pedagogía profana. Buenos Aires: Miño y Dávila.

Larrosa, J. \& Skliar, C. (Eds.). (2009). Experiencia y alteridad en educación. Argentina: Homo Sapiens.

Lévinas, E. (1977). Totalidad e infinito. Salamanca: Sígueme.

Lévinas, E. (1987). De otro modo que ser, o más allá de la esencia. Salamanca: Sígueme.

Lévinas, E. (2000). Ética e infinito. Madrid: Machado Libros.

Lévinas, E. (2006). De la existencia al existente. Madrid: Arena Libros.

Lukács, G. (1970). El alma y las formas. Barcelona: Grijalbo. 
Masschelein, J. \& Simons, M. (2014). Defensa de la escuela. Buenos Aires: Miño y Dávila.

Maturana, H. (1998). Emociones y lenguaje en educación y política. Santiago: Noreste.

Meirieu, F. (1998). Frankenstein educador. Barcelona: Laertes.

Mínguez, R. (2012). La responsabilidad educativa en tiempo de crisis. Edetania: Estudios y Propuestas Socio-educativas, 42, 107-125.

Noddings, N. (2003). Caring: A Feminine Approach to Ethics and Moral Education. Berkeley: University of California Press.

Okuda, M. \& Gómez, C. (2005). Métodos en investigación cualitativa: triangulación. Revista Colombiana de Psiquiatría, XXXIV(1), 118-124.

Skliar, C. (2018). Pedagogías de las diferencias. Buenos Aires: Noveduc.

Sloterdijk, P. (2014). Esferas I. Madrid: Siruela.

Van Manen, M. (2003). Investigación educativa y experiencia vivida. Barcelona: Idea Books.

Van Manen, M. (2010). El tacto en la enseñanza. Barcelona: Paidós.

Van Manen, M. (2015). El tono en la enseñanza. Barcelona: Paidós.

Wild, R. (2006). Libertad y límites. Amor y respeto. Barcelona: Herder.

Zambrano, M. (2011). Notas de un método. Madrid: Tecnos. 